\title{
Mixed methods study examining work reintegration experiences from perspectives of Veterans with mental health disorders
}

\author{
Marina Kukla, PhD; ${ }^{1-2^{*}}$ Nicholas A. Rattray, PhD; ${ }^{1,3}$ Michelle P. Salyers, $\mathbf{P h D}^{\mathbf{2 , 4}}$ \\ ${ }^{1}$ Health Services Research and Development, Center for Health Information and Communication, Richard L. Roudebush \\ Department of Veterans Affairs Medical Center, Indianapolis, IN; Departments of ${ }^{2}$ Psychology, and ${ }^{3}$ Anthropology, \\ Indiana University-Purdue University, Indianapolis, IN; ${ }^{4}$ ACT Center of Indiana, Indianapolis, IN
}

\begin{abstract}
Recent findings have demonstrated that reintegration for Veterans is often challenging. One difficult aspect of reintegration - transitioning into the civilian workplace-has not been fully explored in the literature. To address this gap and examine work reintegration, this mixed methods study examined the perspectives of Veterans with mental health disorders receiving Department of Veterans Affairs healthcare. Forty Veterans rated factors that affect work success; participants also provided narratives on their most and least successful work experiences. We used $t$-tests and qualitative analysis to compare participants who did and did not serve in combat. Several themes relevant to work reintegration emerged in the narratives, particularly for Veterans who served in combat. An array of work difficulties were reported in the months following military discharge. In addition, Veterans who served in combat reported significantly more work barriers than Veterans who did not serve in combat, particularly health-related barriers. In conclusion, Veterans with mental health disorders who served in combat experienced more work reintegration difficulty than their counterparts who did not serve in combat. The role of being a Veteran affected how combat Veterans formed their self-concept, which also shaped their work success and community reintegration, especially during the early transition period.
\end{abstract}

Key words: combat, employment, mental health, posttraumatic stress disorder, reintegration, self-concept, severe mental illness, transition, Veterans, work.

\section{INTRODUCTION}

For Veterans of recent conflicts, reintegration into civilian life can be challenging. Sayer et al.'s national survey found that one-quarter to more than one-half of Operation Enduring Freedom (OEF) and Operation Iraqi Freedom (OIF) Veterans receiving Department of Veterans Affairs (VA) healthcare experienced reintegration difficulties in a variety of domains [1]; more than 90 percent of Veterans also reported interest in services to aid the readjustment process. Another study estimated that more than 70 percent of soldiers returning from combat in OIF experienced at least one readjustment stressor [2]. Similarly, a recent review of literature concluded that while many Veterans are able to successfully readjust to the civilian world, a subset of Veterans struggle in major life areas, including legal problems, strained interpersonal and family relationships, unstable housing, and employment difficulties [3]. Other studies have considered reintegration

Abbreviations: $\mathrm{OEF}=$ Operation Enduring Freedom, OIF = Operation Iraqi Freedom, PTSD = posttraumatic stress disorder, $\mathrm{SD}=$ standard deviation, $\mathrm{SMI}=$ severe mental illness, $\mathrm{VA}=$ Department of Veterans Affairs, VAMC $=$ VA medical center.

*Address all correspondence to Marina Kukla, PhD; Richard L. Roudebush VAMC, 11H 1481 W. 10th St, Indianapolis, IN 46202; 317-988-3330; fax: 317-988-5290.

Email: mkukla@iupui.edu

http://dx.doi.org/10.1682/JRRD.2014.11.0289 
alongside mental health; young Veterans receiving VA care have troubling rates of posttraumatic stress disorder (PTSD), depression, and substance use disorders [4]. Rates of suicide are also higher in Veterans than in the general population [5]. Also alarming, a greater number of postdeployment readjustment stressors in members of the National Guard who participated in recent conflicts were associated with a higher risk of suicide [6].

While previous studies have begun to offer evidence of reintegration problems, the state of knowledge in this area is incomplete. Specifically, there is no consensus definition and no gold standard for measuring community reintegration [7]. In addition, some prior studies have reduced the construct of reintegration difficulty to a one-item assessment, with little attention to the complexity and nuance involved in the dynamic process of reintegration [1]. In response to these issues, the VA Rehabilitation Research and Development Service developed a work group to examine Veteran community reintegration, a stated VA priority [7]. Findings from the work group highlighted the lack of adequate research in this area and the need to explore and identify core elements of community reintegration. These conclusions also underscored the importance of assessing the subjective experience of reintegration to more fully capture individual preference, choice, and satisfaction with participation in life roles [7].

The current study contributes to objectives of the VA work group by examining subjective experience pertaining to a central component of reintegration-participation in the workforce [7]. Work reintegration is a particularly crucial area of study for several reasons. First, productive activity, including work, is a major adult role in our society. In addition, past findings have demonstrated that Veterans struggle in the area of vocational functioning [8]; this burden of unemployment is particularly heavy for those Veterans with families, who have larger financial responsibilities and psychosocial stressors, such as the lack of reliable transportation and inadequate housing [6,9]. Furthermore, one-third of OIF Veterans report work problems, including job loss upon returning from deployment; this is especially problematic among those Veterans who have sought mental health care [2]. Similarly, employed Veterans with mental illness are more likely to be working part-time rather than full-time [10]. Relatedly, the link between PTSD in combat Veterans and work dysfunction is well established
[11-14]. Veterans with PTSD also earn significantly lower wages than Veterans without PTSD [15].

The Veteran role is another important issue to consider with regard to reintegration. Specifically, one's sense of self, or self-concept, as defined through one's role as a Veteran may have a substantial impact on community reintegration long after returning from combat or separating from the military [16]. With regard to work, this notion is supported by past findings indicating that the meaning of work varies across persons according to their self-concept [17]. In this case, self-concept is strongly linked with the Veteran role, particularly following combat experiences and deployments to war zones, which may intensify and substantially alter self-experience [18] or how one views various aspects of him- or herself and his or her life story over time. Subsequent to these lifechanging experiences in the combat zone, one may identify as a soldier, sailor, marine, etc., more strongly than with other adult or civilian life roles [19]; these war and deployment experiences may also facilitate an increased experience of camaraderie and brotherhood/sisterhood among those who served alongside one another and among Veterans in general. As a result, interacting with and understanding civilians can be a difficult process, which can extend into the workplace. Furthermore, reintegrating into civilian life also involves identity renegotiation [20], consisting of a changing sense of self, making meaning of military and war experiences [18], and integrating military experiences with prior self-concept and newly formed circumstances, e.g., a new civilian job or career [16]. Taken together, this literature suggests that work reintegration in light of the Veteran role is a potentially crucial area that warrants further exploration.

In response to this gap in the literature, this study sought to explore the perspectives of Veterans with mental health disorders about work reintegration using a mixed methods approach. Specifically, subjective experiences of work were examined through an inductive emergent approach, seeking to gain a richer understanding of themes of reintegration in the context of work. Second, work reintegration themes were compared between Veterans who served in combat and Veterans who did not participate in combat. As discussed, the experiences of war are life-altering and have been demonstrated to disrupt self-experience and personal narrative [21]. In addition, studies have found that across eras, Veterans who serve in combat tend to have more problematic health and psychosocial outcomes than Veterans who did not serve in 
combat [22]. However, the mechanisms explaining these complex outcomes are not fully understood. We suggest that the early reintegration period as it relates to sense of self is critical in these processes. Therefore, we hypothesized that Veterans with combat exposure would have more salient narratives of work reintegration and, specifically, reintegration stories pertaining to self-concept and their role as a Veteran. In contrast, we expected that Veterans without combat experiences would discuss fewer themes inherent to work reintegration and their role as a Veteran. Lastly, ratings of factors affecting work success were compared between combat and noncombat Veterans in an exploratory fashion in order to further examine work reintegration differences between the groups.

\section{METHODS}

\section{Design}

This mixed methods study is a secondary analysis of a parent study that examined the work perspectives of 40 Veterans receiving mental health care at a VA medical center (VAMC) in an urban Midwestern city [23]. Veterans were recruited from three outpatient mental health clinics specializing in the treatment of severe mental illness (SMI), PTSD, and general outpatient mental health care. Through in-person interviews and a written survey, we collected background information, work history, ratings of factors influencing work success and failure in the community, and narratives of work experiences. Reintegration experiences that emerged in narratives of work experiences were examined through ratings of factors affecting work success.

\section{Sampling}

Veterans were eligible for the study if they had a chart diagnosis of PTSD or a diagnosis falling under the umbrella of SMI (bipolar disorder, major depressive disorder, or schizophrenia spectrum disorder) as documented in the electronic medical record. Both employed and unemployed Veterans were recruited in order to increase variability of the sample and capture a wide range of work reintegration experiences. Veterans were excluded from the study if they were working in a noncompetitive work position or had a severe medical condition, dementia, or other serious cognitive impairment that would prevent participation in the study. Veterans were not excluded from the study if they had a comorbid diag- nosis of a substance use disorder. Convenience sampling was used; sampling ceased after 40 Veterans chose to participate. The participation rate was 58.8 percent $(40$ out of 68 Veterans who were invited chose to participate).

\section{Procedure}

Recruitment was conducted with the assistance of clinicians working in VA mental health clinics. After clinicians were provided study information, they approached eligible Veterans about the study. Interested Veterans were referred to study personnel, who then scheduled times to review consent procedures and conduct interviews. The surveys and interviews were conducted during one meeting with the participant by either the first author (a clinical psychologist) or a research assistant (a doctoral student in clinical psychology). The clinical psychologist conducted 30 interviews/surveys, and the research assistant conducted 10 interviews/surveys. After obtaining written informed consent, we collected survey information and conducted narrative interviews in which participants discussed their most and least successful competitive work experiences. Veterans were paid $\$ 30$ for participating in the study.

\section{Measures}

Participant background characteristics collected included sex, ethnicity, educational attainment, mental health diagnosis, marital status, disability status, income level, residential status, and military background. Work history information included work status (competitively employed or unemployed), average number of hours worked per week, and wage rate worked during the past 6 mo.

The survey of work factors consisted of 20 items scored on a Likert scale probing the degree to which the factors played a role in Veterans' work success [23]. For each item, participants were asked to respond to the following question: "To what extent do the following play a role in your ability to work in a competitive job?" The scale ranged from $0=$ "does not play a role" to $4=$ "plays a very large role." The total scale score ranged from 0 to 20. Participants were then asked to indicate whether each factor was helpful or harmful. For instance, "coworker relationships" could play a large or small role and could be perceived as helpful or harmful to work success. The measure was found to have good psychometric properties [23].

Narrative interviews asked participants to first tell a story about a time when they felt they were successful in 
employment and maintained a competitive job for at least 6 mo. Next, participants were asked to tell a story about a time when they struggled to find or keep a competitive job in the community. Veterans were probed for more information when appropriate. To ensure more thorough identification of work factors, the interviews were concluded with the following three open-ended questions: "Are there any other things that you have not already mentioned, related either to the job directly or other circumstances, which help you to keep your job?"; "Are there any other things that could make it difficult for you to keep your job for a long time?"; and "Are there any other things that you have found helpful to make you successful in your career in general?"

\section{Quantitative Data Analysis}

All quantitative analyses were run using SPSS version 20 (IBM; Armonk, New York). Preliminary analyses checked the normality of the data and characterized the background of the sample using descriptive statistics. These results indicated that the data were fairly normal and assumptions of statistical tests were met, thus parametric statistics were used. Total scores of barriers and facilitators were calculated by summing the scores on all items that scored $\geq 1$ (played at least some role in work success) as either helpful (work facilitators) or harmful (work barriers). Next, independent group $t$-tests compared the combat and noncombat groups on the total number of perceived work barriers and work facilitators as well as individual barriers and facilitators. Significance values were set at 0.05 . The effect size used was Cohen $d$ : 0.2 represents a small effect, 0.05 a medium effect, and 0.08 a large effect.

\section{Qualitative Data Analysis}

Qualitative analyses of open-ended questions and narrative interviews followed an inductive, consensusbased approach informed by grounded theory [24]. The qualitative software program ATLAS.ti (Scientific Software Development $\mathrm{GmbH}$; Berlin, Germany) was used to organize data and aid analysis. First, two study authors independently read interview transcripts and identified preliminary emergent themes relevant to work reintegration using an open coding approach. The coders then met and discussed preliminary codes in an iterative process to generate a consensus codebook, including detailed descriptions of each (see Figure for a listing of codes and descriptions of each code). Next, we used this codebook to rate all transcripts on the presence or absence of the codes (focused coding); dominant themes evidenced through salience and/or frequency were identified. Text segments were coded using multiple codes if appropriate; constraints were not placed on the number of codes that could be applied to a text segment, consistent with the focused coding approach. Coding segment length was determined based on meaning, with each segment representing a complete idea. Lastly, targeted analyses examined differences between the combat and noncombat groups on dominant themes. For this portion of the analyses, the coded text segments were examined and the types of quotations across the two groups were systematically compared to identify patterns. The codes were divided among the two coders, and summaries were written of narrative content pertaining to each code. Every third transcript was coded by both coders to maintain coding consistency; the coders then met to discuss the coding, resolve discrepancies, and arrive at consensus around recurrent themes.

\section{RESULTS}

\section{Sample Descriptives}

As displayed in the Table, the sample included 40 Veterans, 21 with military combat experience and 19 without combat experience. Among Veterans with combat experience, two-thirds $(n=14)$ served in the Persian Gulf war, OEF, OIF, and/or Operation New Dawn. Six Veterans $(28.6 \%)$ participated in combat during the Vietnam war and one during the Iranian hostage crisis of 1979 (4.8\%). Veterans without combat experience served during peace time; 18 out of 19 served during the postVietnam era, preceding the Persian Gulf war (94.7\%). One participant $(5.3 \%)$ served during the United States invasion of Grenada, but did not participate in combat. Furthermore, only 39 participants completed the narrative interview, as one Veteran who participated in combat during the Vietnam war chose to complete the interview at a different time, but did not return. Additional background characteristics and current work status of the sample are shown in the Table.

\section{Quantitative Analyses}

Between-groups analyses revealed that Veterans who served in combat and Veterans who did not serve in combat differed on the total number of perceived barriers to work success, such that those who served in combat experienced significantly more total work barriers (mean \pm standard 


\begin{tabular}{|c|c|}
\hline Code & Description \\
\hline Culture Fit & $\begin{array}{l}\text { Describes the fit between the culture of the military and civilian workplace culture } \\
\text { and work climate. This may also include fit between the Veteran's preferred } \\
\text { culture and the civilian workplace culture (e.g., desire for structure in the } \\
\text { civilian workplace, teamwork, camaraderie, etc.). }\end{array}$ \\
\hline Early Transition & $\begin{array}{l}\text { Describes experiences after returning from deployment and/or after separation } \\
\text { from the military. Themes often included stories of moving into the civilian } \\
\text { working world. For many combat Veterans, this was a tenuous time filled with } \\
\text { uncertainty regarding how to proceed and move from being a soldier, sailor, or } \\
\text { marine into the aforementioned civilian roles. }\end{array}$ \\
\hline $\begin{array}{l}\text { Employer } \\
\text { Perceptions }\end{array}$ & $\begin{array}{l}\text { Describes employers' perceptions of Veterans and particularly Veterans with } \\
\text { mental health disorders; describes employers' tendency to minimize the } \\
\text { experience of Veterans as pertinent and applicable to the civilian job. }\end{array}$ \\
\hline $\begin{array}{l}\text { Interpersonal } \\
\text { Network }\end{array}$ & $\begin{array}{l}\text { Describes the role of Veterans' family, friends, and others; in many cases, these } \\
\text { persons provided support and helped to compensate for mental health } \\
\text { symptoms and cognitive deficits (e.g., memory problems). Also described are } \\
\text { difficult and tenuous interpersonal interactions on the job, particularly with } \\
\text { nonmilitary persons. }\end{array}$ \\
\hline Life Purpose & $\begin{array}{l}\text { Describes Veterans' need for purpose frequently sought through meaningful work } \\
\text { activity and perceiving that one is making a contribution, similar to the } \\
\text { important contribution made while in the military. }\end{array}$ \\
\hline Mental Health & $\begin{array}{l}\text { Describes the ways that mental health and cognitive impairments influence the } \\
\text { process of reintegration. }\end{array}$ \\
\hline $\begin{array}{l}\text { Personal } \\
\text { Reintegration }\end{array}$ & $\begin{array}{l}\text { Describes reintegration themes not explicitly related to work, such as transitioning } \\
\text { back into expected roles as a spouse, parent, student, etc. }\end{array}$ \\
\hline Physical Health & Describes the ways that physical health affects reintegration success. \\
\hline $\begin{array}{l}\text { Reintegration } \\
\text { Expectations }\end{array}$ & $\begin{array}{l}\text { Describes Veterans' expectations of leaving the military and expectations of the } \\
\text { reintegration process; many Veterans described a discrepancy between their } \\
\text { expectations and the reality of reintegration. }\end{array}$ \\
\hline Self-Experience & $\begin{array}{l}\text { Describes the interaction between reintegration and self-experience, or how one } \\
\text { thinks, feels, and experiences the world, including what happens to them and } \\
\text { their interactions and relationships with others. Many Veterans discussed } \\
\text { issues of self-esteem and self-confidence and how the military affected their } \\
\text { lives and helped shape who they are and how they define themselves. Also } \\
\text { includes themes of the impact of military experiences on Veterans' view of } \\
\text { themselves. }\end{array}$ \\
\hline $\begin{array}{l}\text { Skills and } \\
\text { Experience Fit }\end{array}$ & $\begin{array}{l}\text { Describes the fit between the skills, experience, and expertise gained in the } \\
\text { military with civilian jobs. Frequently, Veterans believed that their skills and } \\
\text { background matched the requirements of the civilian jobs, but employers } \\
\text { disagreed. In other narratives, Veterans described how their military job } \\
\text { prepared them for their civilian job. }\end{array}$ \\
\hline
\end{tabular}

Figure.

Qualitative codebook of work factors as barriers and facilitators.

deviation $[\mathrm{SD}]=29.15 \pm 11.23)$ than those who did not $($ mean $\pm \mathrm{SD}=18.94 \pm 10.41 ; t(34)=-2.80, p=0.008, d=$ $-0.94)$. We examined this finding at the item level and discovered that Veterans with combat experience reported significantly more physical health (mean $\pm \mathrm{SD}=3.76 \pm$ $1.48 ; t(38)=2.32, p=0.03, d=-0.75)$ and cognitive 
Table.

Background characteristics of Veterans with and without combat experience. Data presented as mean \pm standard deviation or $n(\%)$.

\begin{tabular}{|c|c|c|}
\hline Variable & $\begin{array}{l}\text { No Combat } \\
\qquad(N=19)\end{array}$ & $\begin{array}{l}\text { Combat } \\
(N=21)\end{array}$ \\
\hline Age (yr) & $52.2 \pm 13.9$ & $49.2 \pm 9.8$ \\
\hline Hours Worked/wk & $34.17 \pm 12.90$ & $36.88 \pm 10.29$ \\
\hline $\begin{array}{l}\text { Current Hourly } \\
\text { Wage* (\$) }\end{array}$ & $11.6 \pm 3.4$ & $20.9 \pm 8.4$ \\
\hline Currently Employed & $9(47.4)$ & $11(52.4)$ \\
\hline Gender: Male & $16(84.2)$ & $17(81.0)$ \\
\hline \multicolumn{3}{|l|}{ Ethnicity } \\
\hline African American & $8(42.1)$ & $6(28.6)$ \\
\hline White & $11(57.9)$ & $13(61.9)$ \\
\hline$>1$ Race & 0 & $2(9.5)$ \\
\hline \multicolumn{3}{|c|}{ Primary Mental Health Diagnosis ${ }^{\dagger}$} \\
\hline Psychotic Disorder & $15(78.9)$ & $2(9.5)$ \\
\hline Mood Disorder & $3(15.8)$ & 0 \\
\hline PTSD & $1(5.3)$ & $19(90.5)$ \\
\hline \multicolumn{3}{|l|}{ Marital Status $\$$} \\
\hline Unmarried & 15 (78.9) & $9(42.8)$ \\
\hline $\begin{array}{c}\text { Married/Living } \\
\text { with Partner }\end{array}$ & $4(21.1)$ & $12(57.1)$ \\
\hline \multicolumn{3}{|l|}{ Education } \\
\hline $\begin{array}{l}\text { Completed High } \\
\text { School/GED }\end{array}$ & $7(36.8)$ & $3(14.3)$ \\
\hline $\begin{array}{l}\text { Some College } \\
\text { (includes Asso- } \\
\text { ciates) }\end{array}$ & $8(42.1)$ & $12(57.1)$ \\
\hline $\begin{array}{l}\text { Completed } \geq 4 \text { yr } \\
\text { College }\end{array}$ & $4(21.1)$ & $6(28.6)$ \\
\hline \multicolumn{3}{|l|}{ Service Branch } \\
\hline Army & $12(63.3)$ & $14(66.7)$ \\
\hline Navy & $5(26.3)$ & 0 \\
\hline Air Force & $2(10.5)$ & 0 \\
\hline Marines & $2(10.5)$ & $9(42.9)$ \\
\hline \multicolumn{3}{|c|}{ Military Conflict/Combat Era } \\
\hline $\mathrm{OIF} / \mathrm{OEF}$ & 0 & $9(42.9)$ \\
\hline Desert Storm & 0 & $5(23.8)$ \\
\hline Vietnam & 0 & $6(28.6)$ \\
\hline Post-Vietnam & $18(94.7)$ & 0 \\
\hline Other Conflict Era & $1(5.3)$ & $1(4.8)$ \\
\hline $\begin{array}{l}\text { VA Disability } \\
\text { Status: Yes }\end{array}$ & $8(42.1)$ & $21(100)$ \\
\hline \multicolumn{3}{|c|}{ 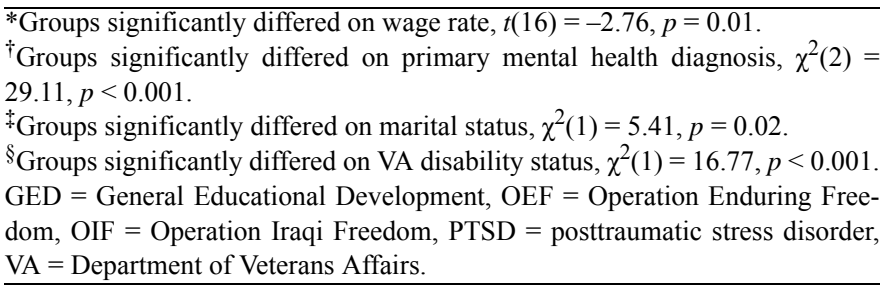 } \\
\hline
\end{tabular}

$($ mean $\pm \mathrm{SD}=4.10 \pm 1.45 ; t(36)=-2.44, p<0.02, d=$ $-0.81)$ problems that interfered with work success than Veterans who did not participate in combat (physical health problems mean $\pm \mathrm{SD}=2.63 \pm 1.61$; cognitive problems mean $\pm \mathrm{SD}=2.94 \pm 1.47$ ). The combat and noncombat groups did not significantly differ on the number of perceived facilitators to work success (mean \pm $\mathrm{SD}=27.62 \pm 13.72$ and $28.33 \pm 16.73$, respectively; $(t(37)=0.15, p=0.88)$. Lastly, we conducted a secondary analysis to assess for possible cohort effects based on combat era: we found no significant differences in total barriers $(t(18)=-0.25, p>0.05)$ or total facilitators $(t(19)=$ $-1.91, p>0.05)$ between Veterans who served during the Persian Gulf war and those who served during previous service eras (e.g., Vietnam).

\section{Qualitative Analyses}

As shown in the Table, qualitative analysis identified several themes that emerged as factors related to work reintegration. These themes can be clustered into the following domains: health (mental and physical), transition (early transition experiences after returning from deployment or separating from the military, personal reintegration into a range of civilian and life roles outside the military, and reintegration expectations), interpersonal (relationships and interactions with others, including in the workplace), self-experience (sense of self defined as a Veteran and life purpose found through work), fit between the military and civilian work setting (skills/ experience translation and educational preparedness), and characteristics of the employer and the workplace (the role of the employer and the workplace culture).

\section{Health Domain}

Health was most often conceptualized as a barrier to work reintegration by both Veterans with and those without combat experience; however, the salience of the types of health issues differed between the two groups. Veterans who served in combat reported both mental and physical ailments, including cognitive impairments, that interfered with their ability to find and keep jobs in the civilian sector. For example, participant 18 discussed the period of time subsequent to his separation from the Marine Corps, “And I was like 21, 22 when I got out. I was medically discharged, so I had a lot of instability with myself knowing that I don't have a career now since I'm injured and, and now I have to start over, like, what do I do? Where do I go? Being a disabled Veteran seemed 
like it was a disabled disadvantage." Veterans who served in combat also noted how issues such as problematic substance use made work reintegration more difficult, often leading to job losses and a pattern of inconsistent employment. Participant 1 described the period after he left the military, "I was drinking and partying a lot and because of my drinking I couldn't hold on to a job...just didn't go in. I felt like drinking. I'd get a paycheck and then miss a couple days, and...do that until they let me go. And then usually I'd draw unemployment until that run out, then I would find another job. But then I decided to get sober... and I had been sober for, like, 17 months but could not find work." In contrast to the narratives of Veterans who served in combat, Veterans who did not serve in combat most often reported mental health problems that led to their discharge from the military or were exacerbated soon thereafter; these problems were often described as "undiagnosed" and/or "untreated" for a period of time, which made finding a job and working in the community very difficult during the transition and beyond.

\section{Transition Domain}

Narratives of early transition after separation from the military or return from deployment were frequently provided by Veterans who served in combat; they described an uncertain time during which they journeyed through the process of navigating back into their interpersonal world with friends, family, and significant others, as well as movement into the civilian employment sector. Veterans offered vivid metaphors that described the challenge of learning to be a civilian again. Further, some participants emphasized the confusion during this time and uncertainty regarding how to proceed; participant 18 stated, "I didn't know when you get kicked out of the service, when I got kicked out... it was just like, well, here you go. You, it just basically seemed like I was walking out of jail....And there was no training besides the training I learned from combat and how to be a leader and, but I mean, not civilian skills." This quote is also consistent with the theme that many Veterans expressed negative reactions toward being discharged prematurely or without adequate preparation. In addition, Veterans expressed the dissonance between expectations of work reintegration upon discharge and actual experiences; participant 39 shared his experience, "I was kind of cocky about it when I got out, thinking all the experience I have, I have a good chance at getting a good job and this really back- fired on me." Participant 15 likewise noted, "Throughout my discharge from the Marines [it] has been hard for me to, to actually keep a job... at least during this time. I was thinking that it would be easy, but it wasn't easy. It was actually harder for me as a Veteran for some reason during this time to find a job, and it seemed like my only place was in the blue collar field...most jobs were temporaries....So I honestly believe during this time it was a factor of just me having a high school diploma wasn't good enough and me serving for my country didn't help any." Veterans expressed disappointment when their expectations for postdeployment work diverged from actual experiences.

In contrast, other stories of early transition centered on the benefits of military experience to the sense of self; many described this as increased self-confidence, selfesteem, and important life skills that translated into everyday life. Participant 20 discussed the factors that facilitated success in his career as a crisis counselor stating, "just the ability of what I learned in the military, how to relate to people, how to talk to people, how to be able to go into a hostile situation and assess it and, and being able to protect people that's involved with it...in the military, you go into combat zones and things like that and you know what your job is. You know what the object is. You know what you need to do and with that it was the same thing, plus it was the fact you got a chance to get out to the community and let them know that you were there to help them and you're there not to hurt them." Similarly, Participant 30 discussed his work success, stating "I think a lot had to do with my training in the Marine Corps...really having developed a great deal of selfconfidence. That plus my education, you know, four years of college I think combined really set a firm groundwork for building a successful career. And also, forming a competent individual - a self-confident and competent individual."

\section{Interpersonal Domain}

The interpersonal domain was hallmarked by narratives of emotional and instrumental support from spouses and other family members. This support tended to serve a compensatory and protective purpose against the negative effects of PTSD and cognitive deficits, setting the stage for successful reintegration into the work setting for Veterans who served in combat. Participant 23 discussed this notion, stating "I got a, a great supportive wife and that's, that's key. That's huge.... She helped me when I 
was pretty nuts at times, helped me tremendously. Always been a great source of strength and support." This Veteran also remarked on another prevalent interpersonal theme - the notion that working with other Veterans is easier because of mutual understanding. In this regard he stated, "Well, many times supervisors that don't have military experience to my level and had difficulties are noncombatants. They don't have a clue what Veterans want or need, even though they're very competent in many areas. And sometimes they're bean counters and all they care about is the numbers...that's more important than the people to some supervisors and that makes it very difficult to have a feeling of teamwork or camaraderie and it's very divisive." A related theme was one of difficult or strained interpersonal interactions with coworkers and supervisors on the job. Participant 18 stated, "Sometimes coworkers can make it difficult, 'cause they don't know what you're feeling or how you're feeling, side effects medically or prescriptionwise. Whatever the case is, some of them don't have an idea and so some of the things that they say are like, what are you thinking? Why would you say something like that? ...just off the wall crap...but I guess civilians, that's just their camaraderie." In addition, Participant 47 stated, "Having PTSD, on day-to-day it's okay but any time that a customer gets irate or hostile it's very hard for me to deal with and not blast back...I've been able to hold it together but my anxiety flares up, I'm shaky and, basically my whole day's just out of sorts...."

\section{Self-Experience Domain}

Self-experience pervaded the narratives of work reintegration in Veterans who served in combat, encapsulating an array of themes. Participants discussed their sense of self and how they viewed and felt about themselves during the reintegration period. For instance, Participant 43 struggled with feelings of worthlessness after returning from deployment, "I came off deployment, I was already depressed a little bit. I had went and sought some counseling behind the scenes because I didn't want anybody to, oh, he's going to the psychiatric people - and so all that together, my self-worth was zero, and my family noticed the difference when I came home. I was just dull. I wasn't that same, happy guy. I changed and didn't feel good about anything. I felt like I was a joke, a loser." Others commented on the way the military has long been a part of how they define themselves and the way this translated into civilian work; in this regard, Participant 3 commented, "I was born to be a Marine. I was born to be in law enforcement. I was born to be a bodyguard, high risk security agent. I love that stuff. I did it ever since I was 18 years old, you know." Relatedly, a notable portion of Veterans reflected on their military experience as the most successful phase in their career, as they felt that they made a meaningful contribution to a worthy and noble cause. Participant 43 described this, "The last time I felt successful was on a deployment to Iraq. I feel like I saved some lives and made a positive difference. One of my mottos was to take over boys and bring them back men. And I tried to change lives, and a lot of people said I did. And there is no finer honor than to lead Americans into combat."

Along the same lines, another important aspect of self-experience is the meaning Veterans derive from their time in the military, including service to their country and brothers and sisters in arms and contributing to the greater good and the collective goals of the military. Participants were most able to integrate this into their selfconcept and form a coherent sense of self during the reintegration period when their civilian work also contributed to a benevolent cause, oftentimes helping other Veterans. In this way, their civilian careers created a strong sense of life purpose. Participant 23 described this as he discussed his job serving Active Duty servicemembers while in the military and Veterans during his civilian pastoral career, "I love my country and I believe in fighting for my country and...dying if need be. Fought twice...love my soldiers and I really enjoy talking about their problems and difficulties in combat and...the rest of life, 'cause life is harder than combat. Combat, every day you either win or lose and if you lose you're dead, you don't worry about it. But if you win, you got the next day. And then when you come back here, sometimes there's no light at the end of the tunnel...." Similarly, Participant 34 commented on her job success helping other Veterans transition into college, stating "...there were three Veterans at the time going to [college] and I feel I helped them a lot. I think overall it went really well and I helped establish a lot of programs that are beneficial for students, well, for Veterans who are trying to matriculate into college and get that transition period together. I helped a lot with that. And that's something I am proud of, that I could help other people when they transitioned from the military, or maybe they've been out of the military and then had a break and then went to school." 


\section{Fit Between Military and Civilian Work Setting Domain}

With regard to the fit between military skills and experiences and the civilian work setting, both Veterans who did and did not serve in combat highlighted a troubling discrepancy. Most often, they believed their military skills and experiences translated well, but civilian employers disagreed. For example, Participant 47, a Veteran who served in combat, explained how the management skills he learned in the military were discounted, "Every job I've applied for they say I don't have enough experience, even though I had the same experience in the military. They don't consider that experience because it wasn't in the civilian sector so it's like I'm starting all over again from high school. I was a mechanic....I was also a squad leader which gives me management skills... and that's not even counted either." Likewise, some Veterans discussed self-doubt and apprehension with regard to their skills and abilities as they shifted from the military to civilian jobs; for example, Participant 43 commented, "I get behind the computer today, and I scan in a folder that has a barcode for a soldier-I can't even hit the buttons without forgetting what I had to do.... I keep forgetting because I get so nervous and I don't want to mess up something for a claim. So, I could go home and tell you how to do it if you're sitting in my house. But when I go to the office today-it was a continuation of yesterday afternoon - I couldn't remember anything. Which is crazy, because I just get nervous. I have no confidence." Moreover, several participants described the reintegration period as one of exploration of work skills and career interests, during which time a number of Veterans chose to respecialize and obtain a college degree in a new civilian field.

\section{Characteristics of Employer and Workplace Domain}

The final domain relevant to work reintegration centered on characteristics of the employer and the workplace. In particular, Veterans who served in combat described how employers' perceptions of Veterans affected the ease with which they were able to reintegrate and achieve work success. For example, Participant 39 commented on his employer's view of the potential for a future deployment, "Yeah, you're military but are you going to take leave because I need someone here...I can't hire you and three months later you're going to Afghanistan or something like that." In contrast, Participant 32 recounted how his employer's decision to hold his job for him during his deployment aided his reintegration when he returned, "I've always worked with my hands and been able to make ends meet by doing construction work. So when I went to Iraq and then came back, of course they held my job, it has good benefits....I've been really blessed to have this job. So, I'm lucky." In addition, an often-mentioned theme was the fit between the culture of the civilian workplace and military culture. Veterans who served in combat heavily emphasized their preference for civilian workplaces that offered more perceived structure, organization, rigidity, and efficiency, in greater alignment with the military style of work. A stronger fit with this aspect of workplace culture led to more successful reintegration; in contrast, a mismatch was associated with more reintegration difficulty. Participant 28 discussed this notion, stating "In the military everything's in a book. If you want to know how to do something, there's a book that tells you how to do it and so I think the military just has the best organization of any corporation anywhere... when I finally reached (military) retirement age, I went to work at several places, this was following the onset of my PTSD and I just could not tolerate working for somebody who was inefficient and disorganized.... And I'd just get mad and quit and so I probably had twelve or fifteen jobs... max time there was three to six months." Participant 40 also commented on the importance of the culture and structure of the civilian work position in comparison to the military; he stated, "If you're an infantry person...you don't ever stop moving. You have so many people in your chain of command telling you what to do all the time, you need a work environment that relates to that or you're going to fail because when you get out, you're just shell shocked." Furthermore, Participant 44 commented on the differences in priorities and approaches between civilian and military jobs; he stated, "When you go to the civilian workplace, civilians take a lot of things for granted...they haven't had their life depend upon the simple things...or other people's lives and so, coming off deployment and going right into the work force.... I had some issues adjusting because the things I thought were important, everybody else was just like 'whatever, we'll get to it someday. It's not a big deal. I'm going home early.' And I thought, well, that's the wrong answer." 


\section{DISCUSSION}

This study used a unique approach to provide insights regarding the work reintegration experiences of Veterans with mental health disorders by complementing quantitative analysis of encountered work barriers with exploration of subjective work experiences of Veterans who served in combat and those who did not. As expected, work reintegration narratives were more frequent in Veterans who served in combat than Veterans who served during peace time. Further, Veterans who served in combat reported more barriers to work success, particularly with regard to physical health and cognitive problems. These findings were expanded by rich qualitative narratives highlighting several areas in which Veterans struggled to reintegrate into the civilian working world both after deployment and after separation from the military. However, Veterans also remarked on the positive impact of their military experience on their selfconfidence, general feelings of competency, and selfefficacy, facilitating success in civilian jobs.

Veterans who perceived their separation from the military to be premature or under circumstances in which they felt ill prepared to move into the civilian world experienced greater difficulty with work reintegration; this was often expressed through a veil of an unstable self-concept and low sense of agency as a competent worker. Often these feelings about oneself went beyond work reintegration and interacted with mental health concerns: Veterans frequently commented on the way mental health symptoms (e.g., PTSD symptoms) interfered with their lives and families and their ability to find and keep work and progress toward a fruitful career path. Moreover, Veterans who were able to integrate their military sense of self (e.g., self as a soldier, sailor, Marine, airman) into their newly forming civilian sense of self experienced a smoother and more successful reintegration into the civilian working world. A more favorable reintegration path was particularly evident for Veterans who found meaning in their civilian jobs (e.g., working with Veterans, contributing to a positive cause, helping the community), had a strong fit between the job and their skills and work preferences (e.g., working with one's hands, performing physical tasks), and perceived a strong match between the civilian workplace culture and the military culture. With regards to the latter, Veterans expressed a strong desire for a culture that fit with the more structured and organized culture of the military, in which tasks and goals are clear and all parties involved work toward the task in an efficient and straightforward manner. Relatedly, particularly during the early transition period, some Veterans expressed a desire to work with Veterans, more so than civilians, given a common work style and demeanor. In addition, they felt a greater sense of camaraderie and shared experience with fellow Veterans. It may also be that working with other Veterans helped some participants extend their service commitment to contributing to something greater than themselves.

Furthermore, Veterans illustrated the mismatch between skills obtained during military service and those perceived by civilian employers as relevant. This problem has been nationally recognized [25] and steps have been taken to remedy it within the governmental sector [26]; initiatives to address this issue have also been spearheaded by a scant number of large private sector companies (e.g., General Electric). In addition, Federal legislation has provided incentives for businesses to hire Veterans with disabilities (including mental illness) who have been recently discharged from the military and those who have been out of work for a substantial period of time; initial evidence suggests that these efforts have made some progress to ameliorate the problem [27]. Moreover, the Post-9/11 Veterans Educational Assistance Act of 2008 affords educational benefits for Veterans wishing to obtain college degrees and/or respecialize skills. However, the current findings highlight an ongoing issue that warrants further examination to better understand the misperceptions of civilian employers and ways in which Veterans with mental health disorders can best accentuate the transferrable nature of their skills and expertise during the job search process. In addition, some Veterans may need to respecialize their skills or seek additional training if their mental and/or physical health ailments prevent them from engaging in civilian vocations for which they were specially trained in the military. These findings suggest the need for a more integrated approach to providing vocational and educational assistance to Veterans with mental and physical illness, such as combining VA supported employment and supported education services [28]. Another important employerrelated theme was the concern by employers regarding future deployments of persons in the National Guard and reserve units who could be called into Active Duty again in the future. While these findings are unique to those still serving, they are consistent with previous findings that civilian employers endorse stigma that dissuade 
them from hiring Veterans, particularly Veterans with mental health disorders [29]; employers have also cited concerns and lack of preparedness pertaining to accommodating Veterans with disabilities, including PTSD [30].

Lastly, our findings point to the protective role of the social network in buffering against poor health, particularly with regard to PTSD and cognitive symptoms. Friends, family, and particularly significant others helped compensate for these difficulties and support reintegration into civilian life. Conversely, the civilian workplace offered an interpersonally challenging and ambiguous work setting for many Veterans who struggled with work reintegration. Interpersonal difficulties on the job were often related to stories of job loss and hesitancy to look for a new job, further delaying work reintegration and career advancement. This finding is supported by research indicating that Veterans with mental illness who have difficulty understanding and responding to social cues tend to have shorter job tenures and earn lower wages [31]. Similarly, unemployed Veterans with physical disabilities have worse social integration than their counterparts who are employed [32]. Taken together, these findings potentially point to an expanded role for integrating family and interpersonal support networks into mental health care, particularly during the early phases of community reintegration [21], in order to buffer against the negative impact of social difficulties.

This study has limitations that are worthy of note. First, the cross-sectional nature of the data precludes drawing firm conclusions; that is, given that data were collected at one point in time, we cannot conclude that the barriers described caused poorer work reintegration or hindered work success. Second, while work reintegration narratives spontaneously emerged as a prominent portion of the range of work success/difficulty narratives, we did not specifically ask about the construct of work reintegration, as to not influence the range of responses and personal conceptualizations of the notion of "work reintegration," consistent with a grounded theory methodology [24]. However, it is possible that this approach may have failed to discover latent narratives addressing work reintegration. Third, narratives of work success and work difficulties were collected more recently to the transition from military to the civilian world for Veterans of recent conflicts, whereas Veterans of more distant conflicts (e.g., Vietnam) and those who served during peace time were asked to recall reintegration events that occurred several years prior or more. This memory bur- den may have led to difficulty recalling the transition period for these Veterans. Along these lines, future research should address the factors most impactful during the early work reintegration period compared with later periods, in which Veterans strive to maintain career success in the face of chronic mental health conditions. In addition, cohort differences may have influenced differences in factors influencing work reintegration. While this study found no differences in work factors between Gulf war Veterans and Veterans from earlier combat eras, the sample was small and the majority of Veterans came from two eras. Further research should use larger and more diverse samples to examine whether Veterans have varying service needs based on their combat era, so that services can be appropriately tailored (particularly for the new generation of Veterans who served in more recent conflicts). Because the participants were primarily white and African American males residing in a Midwestern city, it is unclear whether these findings would generalize to women and Veterans of other ethnic origin and geographical locations (i.e., rural).

\section{CONCLUSIONS}

In summary, this study goes beyond existing reintegration literature by demonstrating a nuanced and multifaceted picture of work reintegration in Veterans with mental health disorders. Reintegration after leaving the military involves multiple transitions that must be managed simultaneously. Further, work reintegration is related to a variety of factors that influence the way Veterans think about themselves, other people, and their ability to succeed in the civilian world postmilitary. These findings also suggest several areas for future study and potential interventions that may enhance the process of reintegration. Notably, it is important to assist Veterans to assimilate military and combat experiences into their changing self-concept, particularly for those who are experiencing poor self-esteem, low self-worth, and a deflated sense of self-confidence and personal agency. Likewise, it is essential to connect and engage these Veterans with effective mental health services; facilitating interpersonal supports is essential. In addition, providing further guidance and resources as Veterans navigate the process of transitioning from the military to the civilian world is critical, especially with regard to the translation of military skills and experiences to the civilian workplace. 
Veterans who perceived greater difficulty attributed to their mental and/or physical illnesses may need a higher level of preparedness and more assistance as they leave the military and move into the civilian world; these Veterans carry the burden of adjusting to both new mental and physical ailments as well as transitioning back into society. Research is in the early stages examining the benefits of evidence-based supported employment services tailored for Veterans with PTSD [33], who often have comorbid physical and cognitive impairments; this promising work will lead to enhanced strategies to address the unique needs of this population, particularly as they transition back into the civilian working world. Finally, the findings regarding stigmatizing employer attitudes toward persons with mental health disorders are consistent with conclusions drawn in prior studies [34]; further investigation of this issue and effective ways to prepare employers to properly work with and accommodate Veterans is urgently needed.

\section{ACKNOWLEDGMENTS}

\author{
Author Contributions: \\ Study design and conception: M. Kukla, M. P. Salyers. \\ Data collection and management: M. Kukla. \\ Regulatory tasks: M. Kukla. \\ Qualitative data analysis and interpretation: M. Kukla, N. A. Rattray. \\ Quantitative data analysis and interpretation: M. Kukla, M. P. Salyers. \\ Manuscript preparation and revision: M. Kukla, N. A. Rattray, M. P. \\ Salyers.
}

Financial Disclosures: The authors have declared that no competing interests exist.

Funding/Support: This material was based on work supported by a 2012 grant from the Indiana Institute for Medical Research, Indianapolis, Indiana.

Institutional Review: This study was approved by the Indiana University-Purdue University Institutional Review Board and the Richard L.

Roudebush VAMC Research and Development committee. All participants provided written informed consent to take part in the study described here.

Participant Follow-Up: The authors will inform participants of the publication of this article.

Additional Contributions: We would like to acknowledge Kelsey Bonfils, research assistant, for her important efforts with regard to data collection and participant recruitment.

\section{REFERENCES}

1. Sayer NA, Noorbaloochi S, Frazier P, Carlson K, Gravely A, Murdoch M. Reintegration problems and treatment interests among Iraq and Afghanistan combat veterans receiving VA medical care. Psychiatr Serv. 2010;61(6): 589-97. [PMID:20513682]

http://dx.doi.org/10.1176/ps.2010.61.6.589

2. Interian A, Kline A, Callahan L, Losonczy M. Readjustment stressors and early mental health treatment seeking by returning National Guard soldiers with PTSD. Psychiatr Serv. 2012;63(9):855-61. [PMID:22706956]

http://dx.doi.org/10.1176/appi.ps.201100337

3. Sayer NA, Carlson KF, Frazier PA. Reintegration challenges in U.S. service members and veterans following combat deployment. Soc Issues Policy Rev. 2014;8(1):3373.

4. Seal KH, Metzler TJ, Gima KS, Bertenthal D, Maguen S, Marmar CR. Trends and risk factors for mental health diagnoses among Iraq and Afghanistan veterans using Department of Veterans Affairs health care, 2002-2008. Am J Public Health. 2009;99(9):1651-58. [PMID:19608954] http://dx.doi.org/10.2105/AJPH.2008.150284

5. Kang HK, Bullman TA. Is there an epidemic of suicides among current and former U.S. military personnel? Ann Epidemiol. 2009;19(10):757-60. [PMID:19628411] http://dx.doi.org/10.1016/j.annepidem.2009.05.004

6. Kline A, Ciccone DS, Falca-Dodson M, Black CM, Losonczy M. Suicidal ideation among National Guard troops deployed to Iraq: The association with postdeployment readjustment problems. J Nerv Ment Dis. 2011;199(12): 914-20. [PMID:22134448] http://dx.doi.org/10.1097/NMD.0b013e3182392917

7. Resnik L, Bradford DW, Glynn SM, Jette AM, Johnson Hernandez $\mathrm{C}$, Wills $\mathrm{S}$. Issues in defining and measuring veteran community reintegration: Proceedings of the Working Group on Community Reintegration, VA Rehabilitation Outcomes Conference, Miami, Florida. J Rehabil Res Dev. 2012;49(1):87-100. [PMID:22492341] http://dx.doi.org/10.1682/JRRD.2010.06.0107

8. Zivin K, Bohnert AS, Mezuk B, Ilgen MA, Welsh D, Ratliff S, Miller EM, Valenstein M, Kilbourne AM. Employment status of patients in the VA health system: Implications for mental health services. Psychiatr Serv. 2011;62(1):35-38. [PMID:21209297] http://dx.doi.org/10.1176/ps.62.1.pss6201_0035

9. Davis LL, Pilkinton P, Poddar S, Blansett C, Toscano R, Parker PE. Impact of social challenges on gaining employment for veterans with posttraumatic stress disorder: An exploratory moderator analysis. Psychiatr Rehabil J. 2014; 37(2):107-9. [PMID:24708195] http://dx.doi.org/10.1037/prj0000058

10. Burnett-Zeigler I, Valenstein M, Ilgen M, Blow AJ, Gorman LA, Zivin K. Civilian employment among recently returning Afghanistan and Iraq National Guard veterans. 
Mil Med. 2011;176(6):639-46. [PMID:21702380]

http://dx.doi.org/10.7205/MILMED-D-10-00450

11. Smith MW, Schnurr PP, Rosenheck RA. Employment outcomes and PTSD symptom severity. Ment Health Serv Res. 2005;7(2):89-101. [PMID:15974155] http://dx.doi.org/10.1007/s11020-005-3780-2

12. Schnurr PP, Lunney CA, Bovin MJ, Marx BP. Posttraumatic stress disorder and quality of life: Extension of findings to veterans of the wars in Iraq and Afghanistan. Clin Psychol Rev. 2009;29(8):727-35. [PMID:19744758] http://dx.doi.org/10.1016/j.cpr.2009.08.006

13. Shea MT, Vujanovic AA, Mansfield AK, Sevin E, Liu F. Posttraumatic stress disorder symptoms and functional impairment among OEF and OIF National Guard and Reserve veterans. J Trauma Stress. 2010;23(1):100-7. [PMID:20127726]

14. Adler DA, Possemato K, Mavandadi S, Lerner D, Chang H, Klaus J, Tew JD, Barrett D, Ingram E, Oslin DW. Psychiatric status and work performance of veterans of Operations Enduring Freedom and Iraqi Freedom. Psychiatr Serv. 2011;62(1):39-46. [PMID:21209298] http://dx.doi.org/10.1176/appi.ps.62.1.39

15. Savoca E, Rosenheck R. The civilian labor market experiences of Vietnam-era veterans: The influence of psychiatric disorders. J Ment Health Policy Econ. 2000;3(4):199-207. [PMID:11967456] http://dx.doi.org/10.1002/mhp.102

16. Smith RT, True G. Warring identities: Identity conflict and the mental distress of American veterans of the wars in Iraq and Afghanistan. Soc Ment Health. 2014;4(2):147-61. http://dx.doi.org/10.1177/2156869313512212

17. Strong S. Meaningful work in supportive environments: Experiences with the recovery process. Am J Occup Ther. 1998;52(1):31-38. [PMID:9426856]

http://dx.doi.org/10.5014/ajot.52.1.31

18. Schok ML, Kleber RJ, Elands M, Weerts JM. Meaning as a mission: A review of empirical studies on appraisals of war and peacekeeping experiences. Clin Psychol Rev. 2008;28(3):357-65. [PMID:17532104] http://dx.doi.org/10.1016/j.cpr.2007.04.005

19. Hoge CW. Once a warrior-Always a warrior: Navigating the transition from combat to home-including combat stress, PTSD, and mTBI. Guilford (CT): Globe Pequot Press; 2010. 328 p.

20. Rumann CB, Hamrick FA. Student veterans in transition: Re-enrolling after war zone deployments. J Higher Educ. 2010;81(4):431-58. http://dx.doi.org/10.1353/jhe.0.0103

21. Demers A. When veterans return: The role of community in reintegration. J Loss Trauma. 2011;16(2):160-79. http://dx.doi.org/10.1080/15325024.2010.519281
22. MacLean A, Elder GH Jr. Military service in the life course. Annu Rev Sociol. 2007;33(1):175-96.

http://dx.doi.org/10.1146/annurev.soc.33.040406.131710

23. Kukla M, Bonfils KA, Salyers MP. Factors impacting work successes in veterans with mental health disorders: A veteran-focused mixed methods pilot study. J Vocat Rehabil. 2015;43(1):51-66. http://dx.doi.org/10.3233/JVR-150754

24. Charmaz K. Constructing grounded theory: A practical guide through qualitative analysis. London: Sage Publications; 2006.

25. Bascetta CA. Military and Veterans' benefits: Observations on the Transition Assistance Program. Washington (DC): U.S. Government Accountability Office (US); 2002. Report No.: GAO-02-914T.

26. Faberman J, Foster T. Unemployment among recent veterans during the Great Recession. Econ Perspect. 2013;37(1).

27. Heaton P. The effects of hiring tax credits on employment of disabled veterans. Santa Monica (CA): Rand; 2012. 14 p.

28. Nuechterlein KH, Subotnik KL, Turner LR, Ventura J, Becker DR, Drake RE. Individual placement and support for individuals with recent-onset schizophrenia: Integrating supported education and supported employment. Psychiatr Rehabil J. 2008;31(4):340-49. [PMID:18407884] http://dx.doi.org/10.2975/31.4.2008.340.349

29. Society for Human Resources Management. Employing military personnel and recruiting veterans: Attitudes and practices [Internet]. Washington (DC): Society for Human Resource Management; 2010. Available from: http:// www.shrm.org/Research/SurveyFindings/Articles/Pages/ EmployingMilitaryPersonnelRecruitingVeterans.aspx

30. Rudstam H, Strobel Gower W, Cook L. Beyond yellow ribbons: Are employers prepared to hire, accommodate and retain returning veterans with disabilities? J Vocat Rehabil. 2012;36(2):87-95.

31. Reddy LF, Kern RS. Supported employment among veterans with serious mental illness: The role of cognition and social cognition on work outcome. Schizophr Res Cogn. 2014;1(3):144-48.

http://dx.doi.org/10.1016/j.scog.2014.09.004

32. Ottomanelli L, Barnett SD, Goetz LL. A prospective examination of the impact of a supported employment program and employment on health-related quality of life, handicap, and disability among Veterans with SCI. Qual Life Res. 2013;22(8):2133-41. [PMID:23345022] http://dx.doi.org/10.1007/s11136-013-0353-5

33. Davis LL, Leon AC, Toscano R, Drebing CE, Ward LC, Parker PE, Kashner TM, Drake RE. A randomized controlled trial of supported employment among veterans with posttraumatic stress disorder. Psychiatr Serv. 2012;63(5): 464-70. [PMID:22307881] http://dx.doi.org/10.1176/appi.ps.201100340 
JRRD, Volume 52, Number 4, 2015

34. Bond GR, Drake RE. Predictors of competitive employment among patients with schizophrenia. Curr Opin Psychiatry. 2008;21(4):362-69. [PMID:18520741]

http://dx.doi.org/10.1097/YCO.0b013e328300eb0e

Submitted for publication November 19, 2014. Accepted in revised form March 4, 2015.

This article and any supplementary material should be cited as follows:
Kukla M, Rattray NA, Salyers MP. Mixed methods study examining work reintegration experiences from perspectives of Veterans with mental health disorders. J Rehabil Res Dev. 2015;52(4):477-90.

http://dx.doi.org/10.1682/JRRD.2014.11.0289

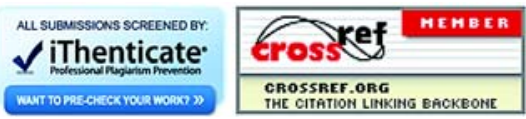

